\title{
EXTENSÃO PETIANA VOLTADA PARA A INICIAÇÃO TECNOLÓGICA DOS ESTUDANTES DO ENSINO BÁSICO
}

DOI: 10.37702/2175-957X.COBENGE.2021.3623

Ronan Marcelo Martins - ronan.martins@cba.ifmt.edu.br

IFMT

Rua Zulmira Canavaros 95

78005-200 - Cuiabá - MT

Luan Dias Rodrigues - luan_ds.rs@hotmail.com

IFMT

rua terra roxa $94 \mathrm{~N}$

78320-000 - Juina - MT

Gabriel Felix da Silva - gabrielfelix.ifmt@gmail.com

IFMT

Av. Dom Orlando Chaves 2896

78117-400 - Várzea Grande - MT

João Pedro Cunha dos Santos - joaopedrocunhasto10@gmail.com IFMT

Rua senador Teotônio Vilela 460

78050-340 - Cuiabá - MT

Resumo: O presente trabalho é o resultado de uma das extensões executadas pelo PET AutoNet no contexto dos estudantes do ensino básico, compreendendo escolas Estaduais, e com os objetivos de despertar vocações e de contribuir para a iniciação tecnológica bem como para o itinerário formativo "formação técnica e profissional" da Base Nacional Comum Curricular (BNCC) do ensino médio. Além disso, a extensão buscou estimular o público-alvo pelas áreas das Engenharias e suas tecnologias. Com estes propósitos, o artigo descreve a metodologia utilizada baseando-se em dois projetos de iniciação tecnológica. O primeiro projeto é denominado de "Oficina de Hardware". O primeiro problema dessa oficina é fazer o acionamento de uma lâmpada, representada por um díodo emissor de luz (led), por chave e pelo sensor $L D R$ e, a solução é a montagem de dois circuitos eletroeletrônicos com uso amplificador operacional LM324. A oficina não é apenas a montagem do circuito eletrônico, é introduzido também noções teóricas 
envolvendo a Lei de Ohm, associação série e paralela de resistores, funcionamento do díodo emissor de luz (led), cálculo da resistência em série com o led, interpretação da curva característica (IXV) do led. Já o segundo projeto "Oficina de Programação Aplicada" está relacionado com a programação de aplicação no controle de um semáforo e no acionamento de uma lâmpada, porém, a solução do problema é por meio da programação do microcontrolador Arduino. Ao final da extensão, é notória a motivação dos estudantes, muito graças a metodologia empregada que coloca os estudantes como protagonistas da aprendizagem.

Palavras-chave: Iniciação Tecnológica; Programação Aplicada; Circuitos Eletroeletrônicos; Ensino Básico; Extensão Universitária. 


\section{EXTENSÃO PETIANA VOLTADA PARA A INICIAÇÃO TECNOLÓGICA DOS ESTUDANTES DO ENSINO BÁSICO}

\section{INTRODUÇÃO}

O presente trabalho é o resultado de uma das extensões executadas pelo PET AutoNet no contexto dos estudantes do ensino básico, compreendendo escolas Estaduais, e com os objetivos de despertar vocações e de contribuir para a iniciação tecnológica bem como para o itinerário formativo "formação técnica e profissional" da Base Nacional Comum Curricular (BNCC) do ensino médio. Além disso, a extensão buscou estimular o públicoalvo pelas áreas das Engenharias e suas tecnologias.

O PET pertence ao Programa de Educação Tutorial (PET)/MEC e a sua abrangência é interdisciplinar, podendo seus integrantes pertencerem aos Cursos das Engenharias de Controle e Automação, Elétrica e Computação como também dos Cursos de Tecnologia em Redes de Computadores e Automação Industrial. O tema norteador do PET é a área da Robótica como estratégia de integrar a interdisciplinaridade presente na sua composição. A estratégia adotada no planejamento e a respectiva execução das suas atividades como, por exemplo, recepção dos calouros, monitoria, sessões técnicas, pesquisa, oficinas técnicas tecnológicas, atividades com a comunidade, ações de caráter coletivo, tais como, "Maratona de Robótica" e a "Olimpíada Brasileira de Robótica" (OBR) eventos) garantem a indissociabilidade ensino-pesquisa-extensão. Em linhas gerais, as ações do PET visam fortalecer a graduação, combater à evasão, promover estímulos nos estudantes para estudos de temas avançados e na formação da consciência da cidadania. O PET há dez anos desenvolve atividades com foco no ensino básico. A experiência permitiu, por exemplo, a execução de curso para professores do ensino básico com foco na programação de robôs por meio do simulador SBotics. Além disso, está previsto a primeira maker faire realizado pelo PET e usando o fab lab institucional, dependendo das condições sanitárias.

Todavia, neste trabalho, o objetivo será a apresentação de relatos associados a metodologia e os resultados obtidos envolvendo dois projetos de iniciação tecnológica implementados na forma de oficinas realizados antes da pandemia. Essas oficinas tecnológicas desenvolvem práticas que estimulem e desenvolvem nos estudantes 0 pensamento tecnológico.

O primeiro projeto está relacionado com hardware e noções de análise de circuitos eletroeletrônicos, permitindo que os participantes manuseiem esses dispositivos. Para tanto, o problema envolve o acionamento de uma lâmpada, representada por um díodo emissor de luz (led), por chave e pelo sensor LDR cuja solução é realizada pela montagem de dois circuitos eletroeletrônicos.

O segundo projeto está relacionado com a programação de aplicação no controle de um semáforo e no acionamento de uma lâmpada, porém, a solução do problema é realizada por meio da programação aplicada peloainterface de desenvolvimento do microcontrolador Arduino. Este projeto procura ilustrar a importância da programação no controle do hardware.

Antes da apresentação da metodologia, destacamos que as referências estão pautadas por e-books e sites com a finalidade de facilitar o apoio à aprendizagem e colocar o estudante como protagonista da aprendizagem. 


\section{METODOLOGIA}

Para que os objetivos fossem alcançados, a metodologia seguiu algumas premissas gerais, isto é:

a) Possibilitar aos participantes o manuseio dos componentes eletroeletrônicos constantes nos experimentos;

b) Levantamento do custo dos componentes e dispositivos eletroeletrônicos pelos estudantes como uma maneira de estimular os estudantes a reproduzi-los em suas casas. Esta etapa é a chamada "Ida às Compras;

c) O uso do programa "fritzing" para montagem dos circuitos eletrônicos de forma a fornecer ao estudante uma melhor compreensão do funcionamento e detalhamento dos componentes usados nas oficinas;

d) Implementação de circuitos eletrônicos de fácil replicação, custo reduzido e muito populares na internet;

e) Os circuitos eletrônicos devem ser práticos e, se possível, lúdicos como é a estratégia adotada aqui, acender e apaga a luz (led) com chave e sensor (LDR), controlar um semáforo, são alguns exemplos. Evidentemente que não é necessário usar estes mesmos casos desde que atendam, num primeiro momento, os qualificadores indicados em d);

f) A programação do hardware é realizada por meio do microcontrolador Arduino (Arduino, 2021);

g) A última etapa é a "Ida às compras" que corresponde a pesquisa de preços dos componentes e dispositivos utilizados.

A implementação da metodologia ocorre por meio de dois projetos de iniciação tecnológica:

1) Projeto1 - Oficina de hardware e;

2) Projeto 2 - Oficina de programação aplicada.

\subsection{Projeto 1 - Oficina de hardware}

Trata-se de uma oficina com duração de 12 horas que tem o propósito de montar o circuito eletroeletrônico, manusear componentes eletrônicos e dar um sentimento de "engenheiros projetistas". Os participantes, no máximo 20, são divididos em equipes de dois a três estudantes. Num primeiro momento, é apresentado o problema e a solução técnica-tecnológica envolvendo duas situações:

Situação 1 - Acionar uma "lâmpada", representada no circuito eletrônico por um díodo emissor de luz (led), por uma chave "botão de pulso" usando um amplificador operacional comparador e;

Situação 2 - Acionar uma "lâmpada", representada no circuito eletrônico por um díodo emissor de luz (led), usando um sensor de luz (LDR) e utilizando o amplificador operacional comparador.

A seguir são fornecidos os detalhes dos procedimentos adotados no desenvolvimento das duas situações mencionadas. 


\subsection{1}

\section{Situação 1 - acionar uma "lâmpada", representada no circuito eletrônico por um díodo emissor de luz (led), por uma chave "botão de pulso" usando um amplificador operacional comparador}

Neste caso, o circuito eletrônico usado como base é o da Figura 1 que está ilustrado usando o software "fritzing".

Figura 1 - Acionamento da lâmpada (led) comparando dois sinais de tensão na entrada do LM324.

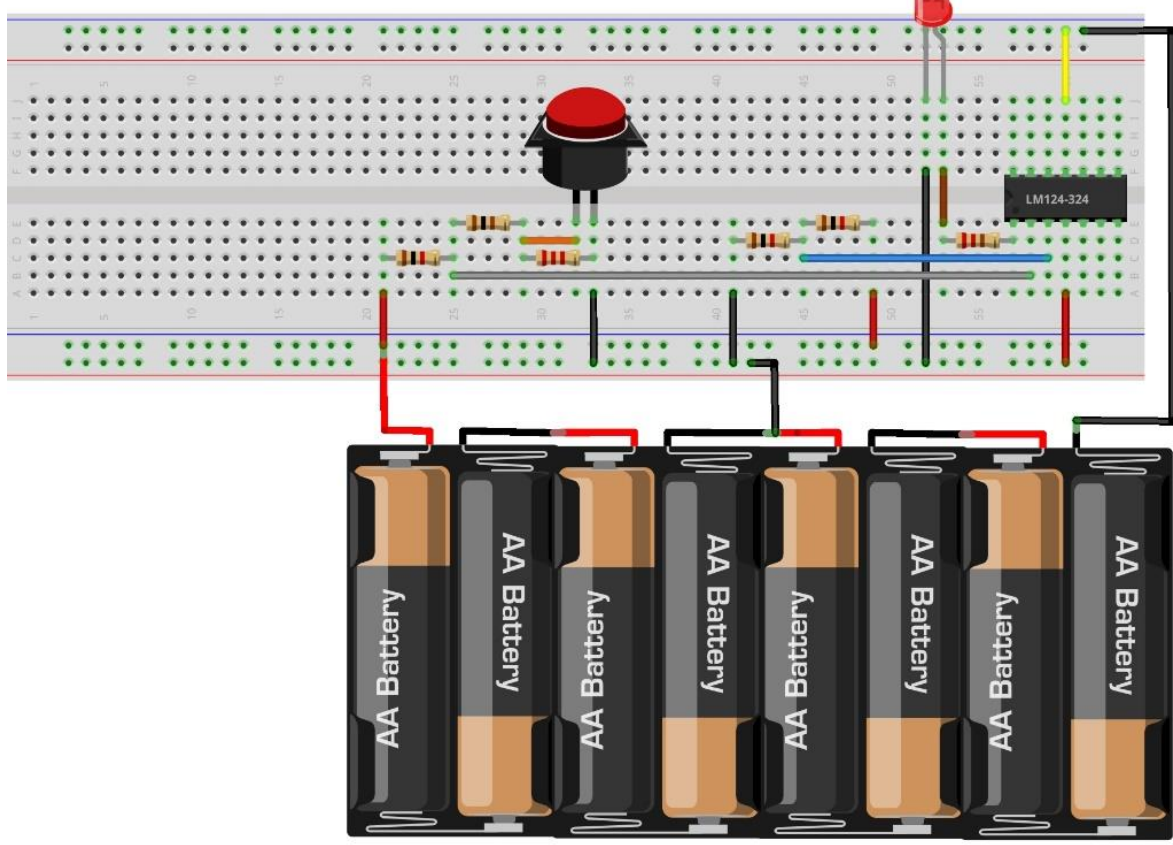

Fonte: Própria.

O circuito eletrônico da Figura 1 utiliza um amplificador comparador LM324 de uso bastante difundido na área de eletrônica e, especificamente, permite comparar dois sinais elétricos que dependendo do valor dos sinais analógicos que chegam nas entradas das portas "não inversora (+)" e "inversora (-)" que, quando comparadas, o led (luz) instalado na porta de saída do comparador acenderá ou não. Especificamente, quando o "botão de pulso (Ch)" for acionado, o sinal elétrico na porta inversora passa a ser menor que o valor de referência (Vref) e a saída do componente LM324 atinge o nível 1, acedendo o led (luz).

Todavia, antes da montagem do circuito eletrônico da figura 1, a oficina oferece noções teóricas envolvendo a Lei de Ohm, associação série e paralela de resistores, funcionamento do díodo emissor de luz (led), cálculo da resistência em série com o led, interpretação da curva característica (IxV) do led, descrição do amplificador operacional comparador e os conceitos relacionados ao funcionamento do amplificador, tais como, tensão de referência (Vref) e tensão de saturação (BENITEZ, 2020).

Para uma melhor compreensão do funcionamento do circuito eletrônico e a aplicação dos conceitos listados no parágrafo anterior, o circuito da Figura 1 é segmentado em três partes.

A "Parte 1" compreende o circuito elétrico da Figura 2 que tem como finalidades: a) definição dos valores de R1 e R2; b) interpretação das cores dos resistores; c) obtenção dos valores da corrente e da tensão elétrica nos terminais de cada resistência em série. São fornecidos os valores das tensões da fonte $(6 \mathrm{~V})$ e de referência (Vref) desejada pelo projetista (3 V). 
Figura 2 - Esquema do circuito elétrico e a representação física para o cálculo de R1, R2 e I.
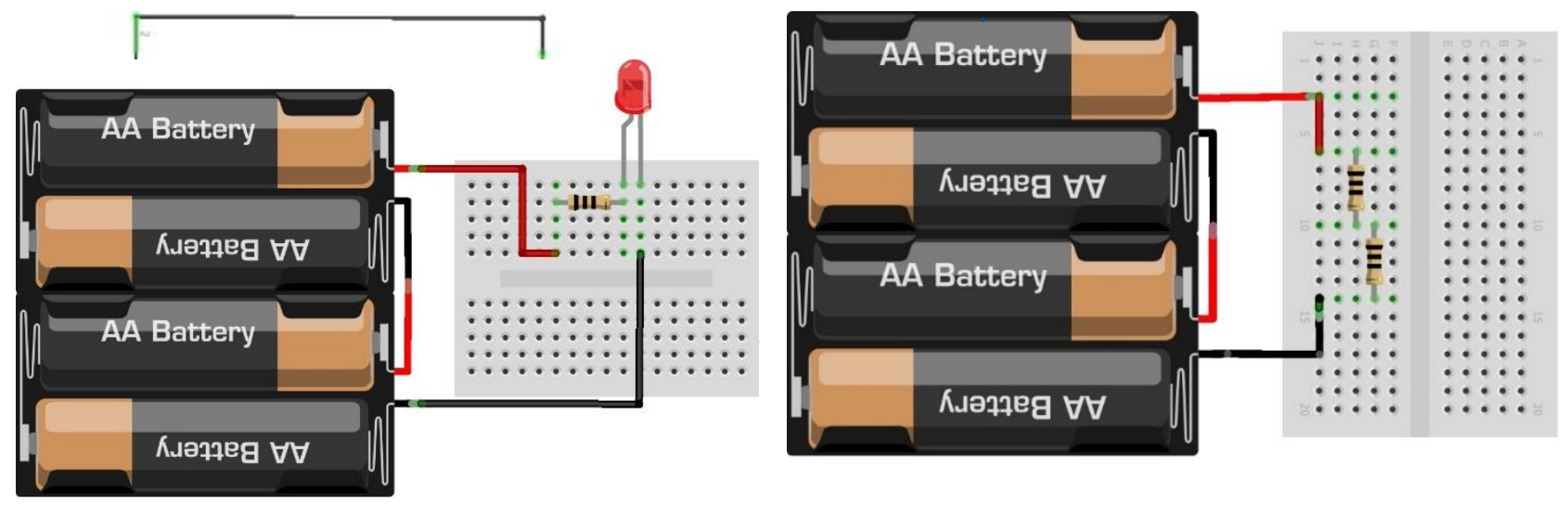

Fonte: Própria

Já a "Parte 2" tem como objetivos a obtenção dos valores da tensão (V1) e da corrente elétrica I para duas condições: 1) com a chave (Ch) ligada e; 2) com a chave (Ch) desliga. Os valores da fonte de tensão e das resistências em série são empregados $6 \mathrm{~V}$, $1 \mathrm{~K} \Omega, 100 \Omega$ e $2,2 \mathrm{~K} \Omega$, respectivamente. $O$ circuito elétrico está mostrado na Figura 3.

Figura 3 - Esquema do circuito elétrico e a representação física para o cálculo de I e V1.
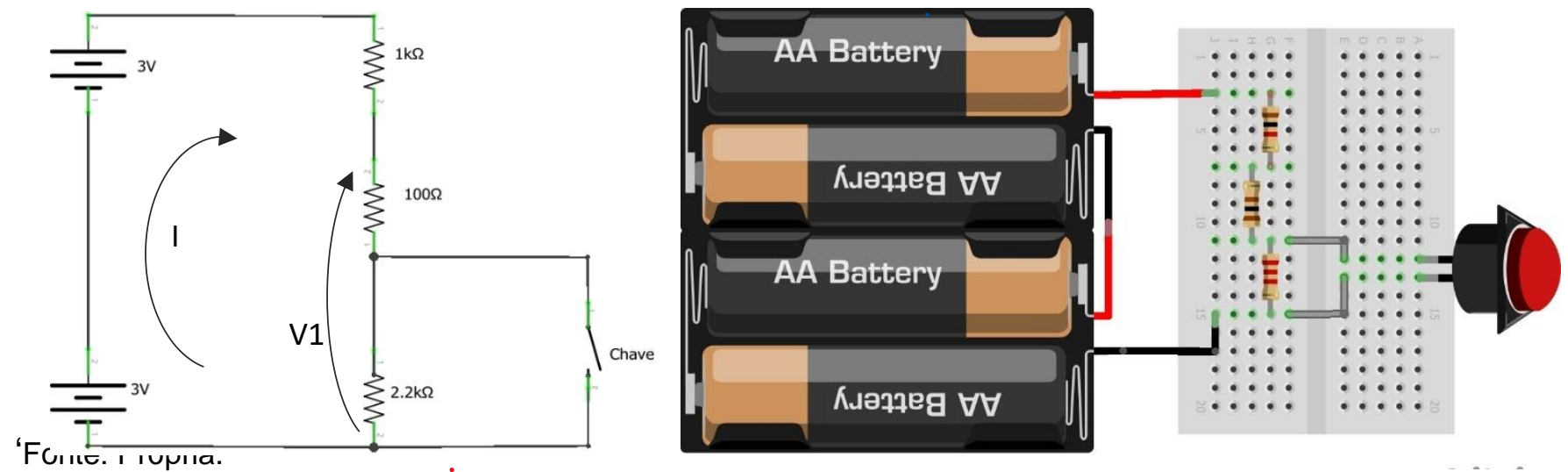

A parte seguinte, "Parte 3", está relacionada ao funcionamento do led e com o cálculo da resistência série com o led bem como a interpretação da curva característica (Vxl) do led (LED, 2021). O circuito eletrônico usado foi o da figura 4.

Figura 4 - Circuito eletrônico utilizado para a definição da resistência R1 em série com o led.
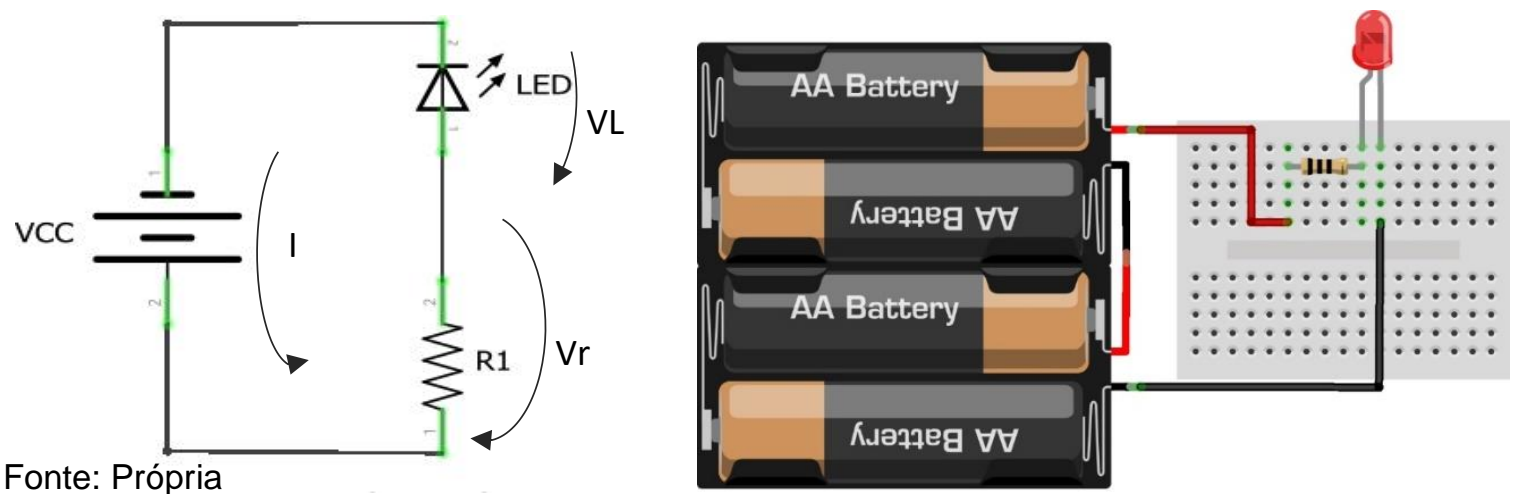

Fonte: Própria 
Posteriormente, é introduzida "Parte 4" que tem como meta descrever a pinagem do circuito integrado LM324 destacado na Figura 5.

Figura 5 - Pinagem do CI LM324.

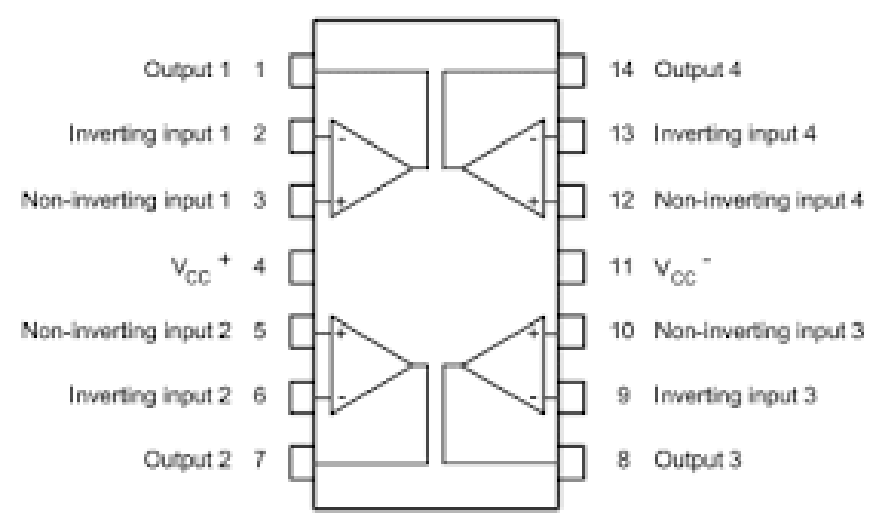

FONTE: https://protosupplies.com/wp-content/uploads/2019/07/LM324-Pinout.jpg

Após essa introdução teórica e prática, os estudantes estão aptos para a fase da montagem do circuito eletrônico da Figura 1 onde são realizadas as análises de funcionamento do respectivo circuito eletrônico.

\subsubsection{Situação 2 - acionar uma "lâmpada", representada no circuito eletrônico por um díodo emissor de luz (led), usando um sensor de luz (LDR) por meio de um amplificador operacional comparador.}

Para esta situação, o circuito eletrônico usado como base é o da Figura 6 que está ilustrado no software "fritzing".

Figura 6 - Acionamento do led(luz) pelo sensor LDR

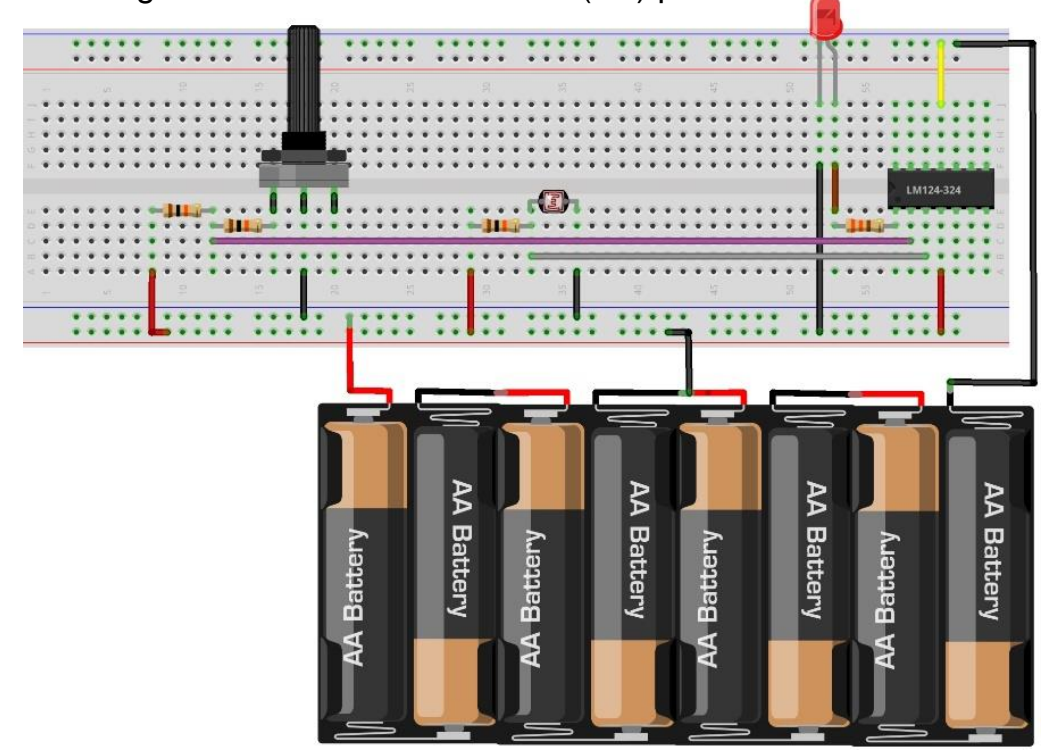

Fonte: Própria. 
Este circuito é uma evolução em comparação ao da Figura 1 pelo fato de que que o mesmo possui uma automação no acionamento do led (luz) por meio de um sensor LDR, sensível à variação de luz. Além disso, permite ajustar a sensibilidade do circuito eletrônico pela instalação de um potenciômetro (POT $10 \mathrm{~K} \Omega$ ) instalado na porta inversora do componente LM324. Desta forma, quando o sensor LDR "sentir" ausência de luz, o sinal lógico na porta "não inversora (+)" do componente eletrônico LM324 atingirá um valor maior que aquele da "porta inversora (-)" e o led (Luz) acenderá.

Como ocorreu na "Situação 1", para uma melhor compreensão do funcionamento do circuito eletrônico da figura 6 é realizado um experimento com o sensor LDR. Para tanto, antes é analisado o comportamento da resistência do LDR em função da intensidade de luz. O circuito eletrônico usado é o da Figura 7 (LDR,2021).

Figura 7 - Circuito eletrônico para análise do funcionamento do LDR.
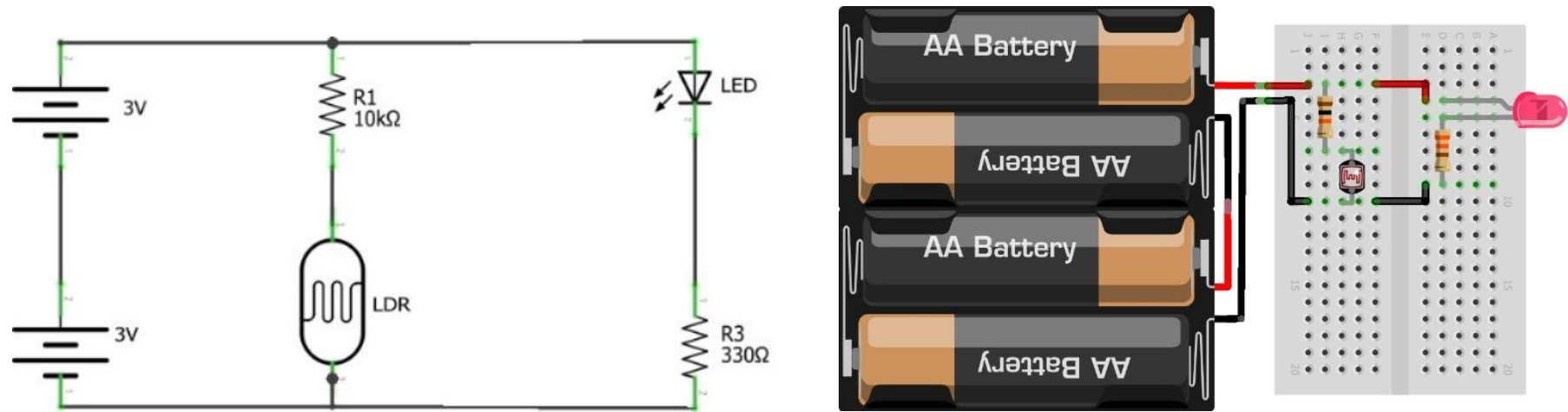

Fonte: Própria.

Dependendo da incidência de luz ambiente no LDR, o led altera a sua luminosidade. Realizado essè procedimento, os estudantes estão aptos a implementar e analisar o funcionamento do circuito eletrônica da Figura 7.

\section{2 . Oficina de Programação Aplicada}

A oficina de programação aplicada ao hardware tem como dispositivo fundamental, o microcontrolador Arduino. As razões da escolha pelo Arduino são conhecidas e destacase algumas delas, como por exemplo, a programação é baseado em software (IDE), o hardware e o software são open source; o microcontrolador tem custo reduzido, é um ambiente de multiplataformas e, sobretudo, é muito popular na internet e com várias aplicações muito interessantes. Isso torna o estudante mais autônomo e protagonista da evolução do seu aprendizado.

A metodologia empregada tem foco na comunicação do Arduino com o hardware a ser controlado bem como noções de programação (Gaier, 2021) do microcontrolador Arduino, tais como, tipos de variáveis (int, bool), significado das instruções pinMode, OUTPUT, LOW, HIGH, digitalWrite, delay, e, as funções setup(), loop(), Serial.begin, Serial.printIn() e analogRead().

Como ocorreu na "Situação 1", é a realizada uma introdução na interface de desenvolvimento da programação do Arduino bem como a apresentação da placa do microcontrolador "Arduino". Nesta etapa, os estudantes executam o "blind" de um led.

$\mathrm{Na}$ sequência, são usados dois casos práticos. O primeiro caso "Programação aplicada em Semáforo" dá ênfase à programação vinculada às portas digitais do Arduino, 
enquanto, o segundo caso "Programação aplicada com LDR" está relacionado com a leitura de sinais analógicos usando o sensor LDR.

\subsubsection{Caso 1 - Programação aplicada em Semáforo}

Esse é muito simples e tem o propósito de familiarização com o Arduino e com o ambiente de programação bem como definir sinais digitais. A lógica de programação não é o foco, os destaques vão para as instruções e funções obrigatórias. O esquema elétrico e a montagem no software "fritzing" estão ilustradas nas Figuras 8 e 9, respectivamente.

Figura 8 - Esquema do circuito eletrônico do projeto "Semáforo" usando Arduino.

Fonte: Própria.

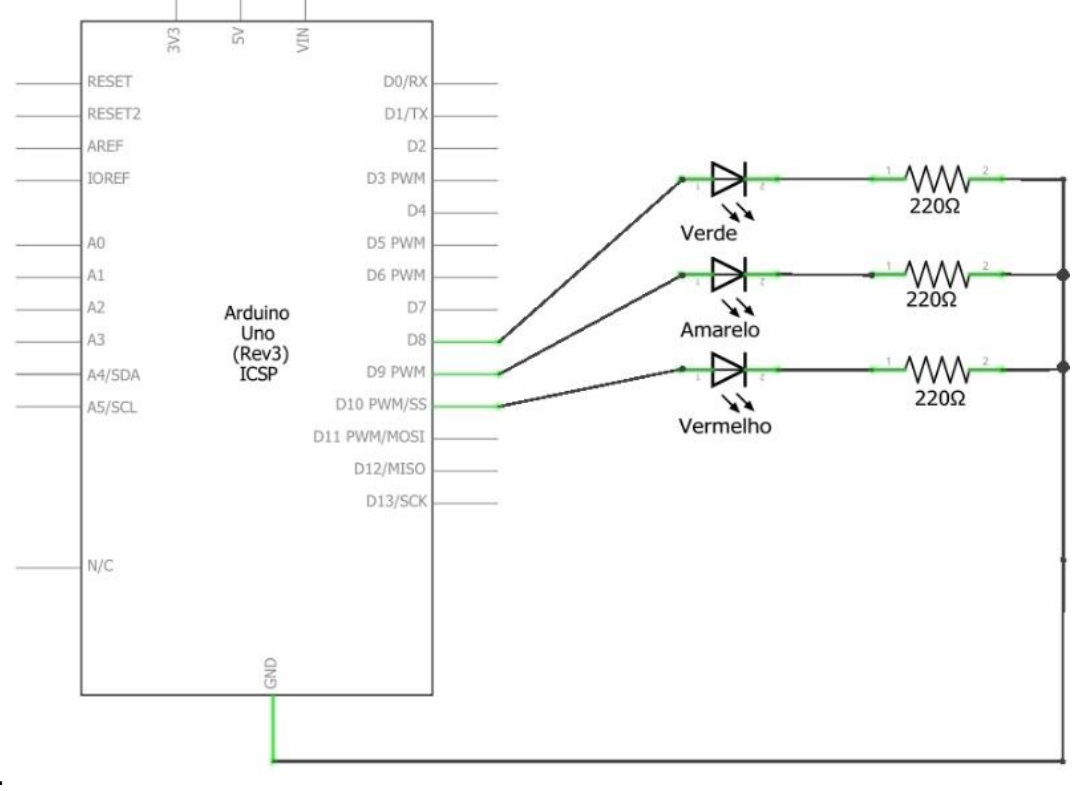

Figura 9 - Circuito eletrônico do projeto "Semáforo" no "fritzing"..

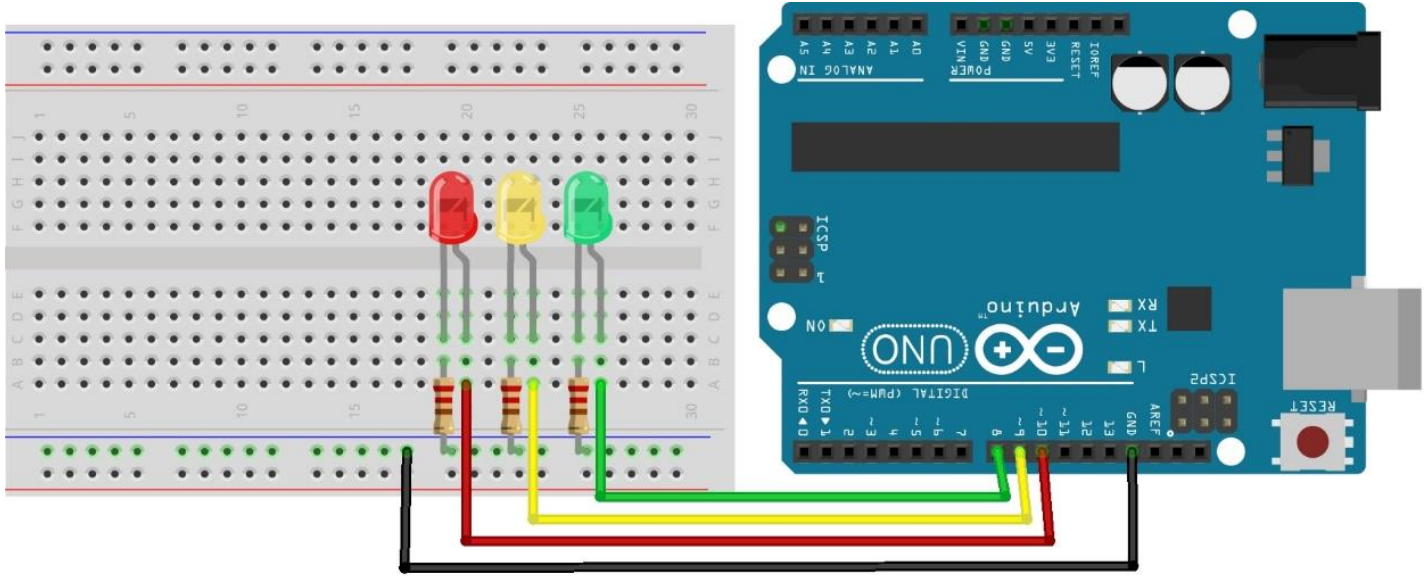

Fonte: Própria.

Já o quadro 1 descreve a programação com destaque às instruções de escrita "digitalWrite" nas portas digitais do Arduino. 
Quadro 1 - Programação projeto "semáforo".

1. int tempoEspera $=5000$; //tempo $5000 \mathrm{~ms}=5$ segundos

2. int pinoVermelho $=10 ; \quad / /$ led vermelho no pino 10

3. int pinoAmarelo $=9 ; \quad / /$ led vermelho no pino 9

4. int pinoVerde $=8 ; \quad / /$ led vermelho no pino 8

5. void $\operatorname{setup}() / /$ definição das portas

6. \{

7. pinMode(pinoVermelho, OUTPUT); // saída

8. pinMode(pinoAmarelo, OUTPUT); //saída

9. pinMode(pinoVerde, OUTPUT); //saída

10. $\}$

11. void loop()

12. $\{$ //inicio do laço

13. digitalWrite(pinoVermelho, $\mathrm{HIGH}$ ); //liga vermelho

14. delay(tempoEspera); //conta tempo

15. digitalWrite(pinoVermelho, LOW); //desliga vermelho

16. digitalWrite(pinoVerde, $\mathrm{HIGH}$ ); //liga verde

17. delay(tempoEspera); //conta tempo

18. digitalWrite(pinoVerde, LOW); //desliga verde

19. digitalWrite(pinoAmarelo, $\mathrm{HIGH}$ ); //liga amarelo

20. delay(3000);

Fonte: Própria.

21. digitalWrite(pinoAmarelo, LOW); //desliga amarela

22. \} // fim do laco

Verifica-se pela programação que o estágio das cores vermelha e verde têm duração de 5 segundos enquanto o tempo do estágio da cor amarela é de 3 segundos. A lógica de programação é bastante e fácil de compreender mesmo para aqueles que nunca programaram. Na sequência é apresentado o caso 2 envolvendo o sensor LDR.

\subsubsection{Caso2 - Programação aplicada com LDR}

Nesse caso, é introduzido um pouco de lógica de programação por meio do uso dos operadores relacionais $(<,>,<=,>=,<>)$ na leitura dos valores do sensor LDR. O esquema elétrico e a montagem no software "fritzing" estão ilustradas nas Figuras 10 e 11, respectivamente.

Figura 10 - Esquema do circuito eletrônico do projeto "LDR" usando Ardưino.

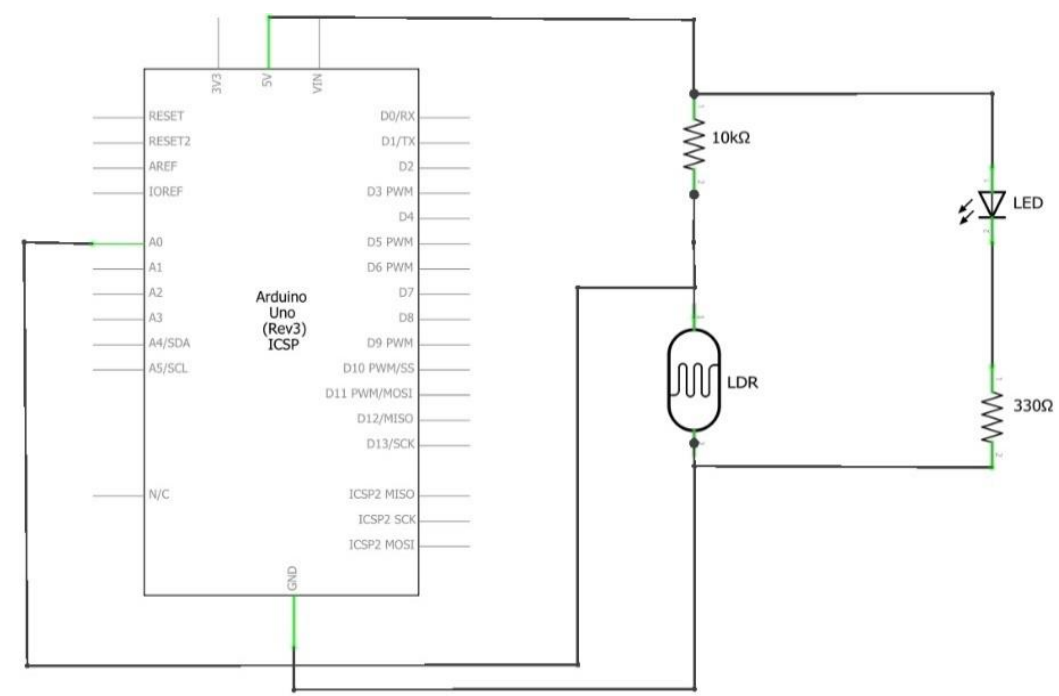


Figura 11 - Circuito eletrônico do projeto "LDR" no "fritzing".

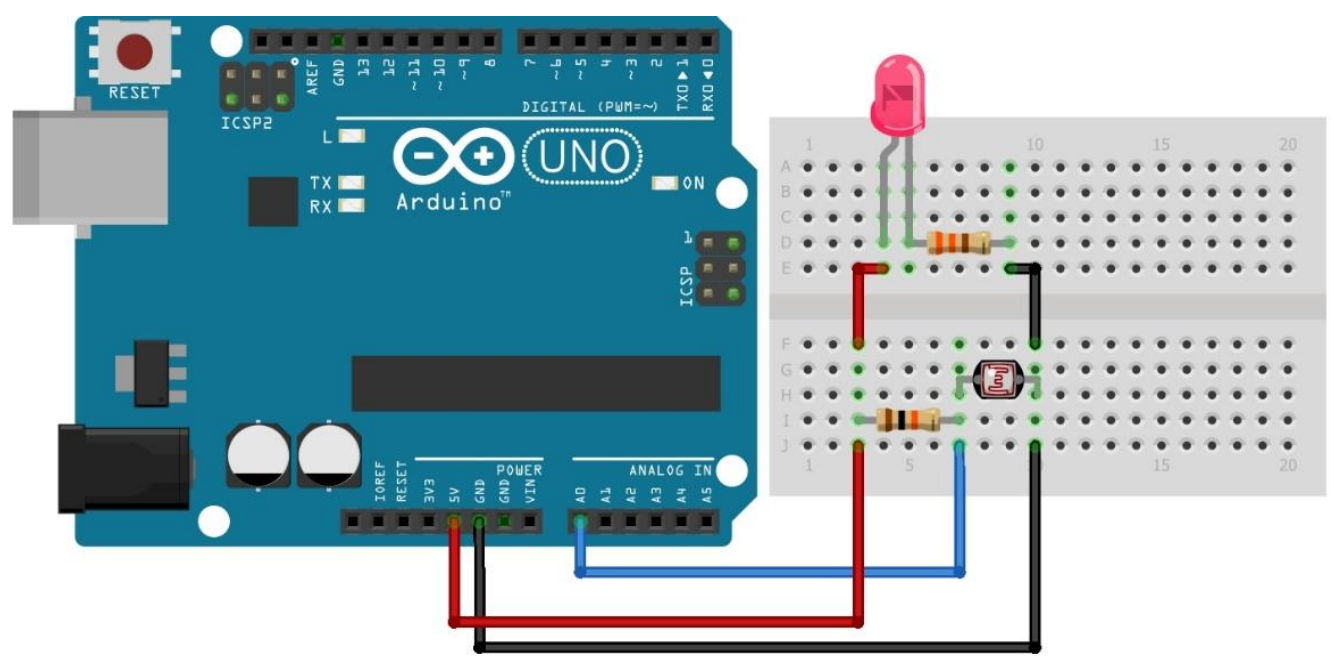

Nas figuras 10 e 11, a porta utilizada para a leitura dos valores do sensor LDR corresponde a A0. Além disso, à medida que a intensidade de luz ambiente sobre o sensor faz variar a luz do led.

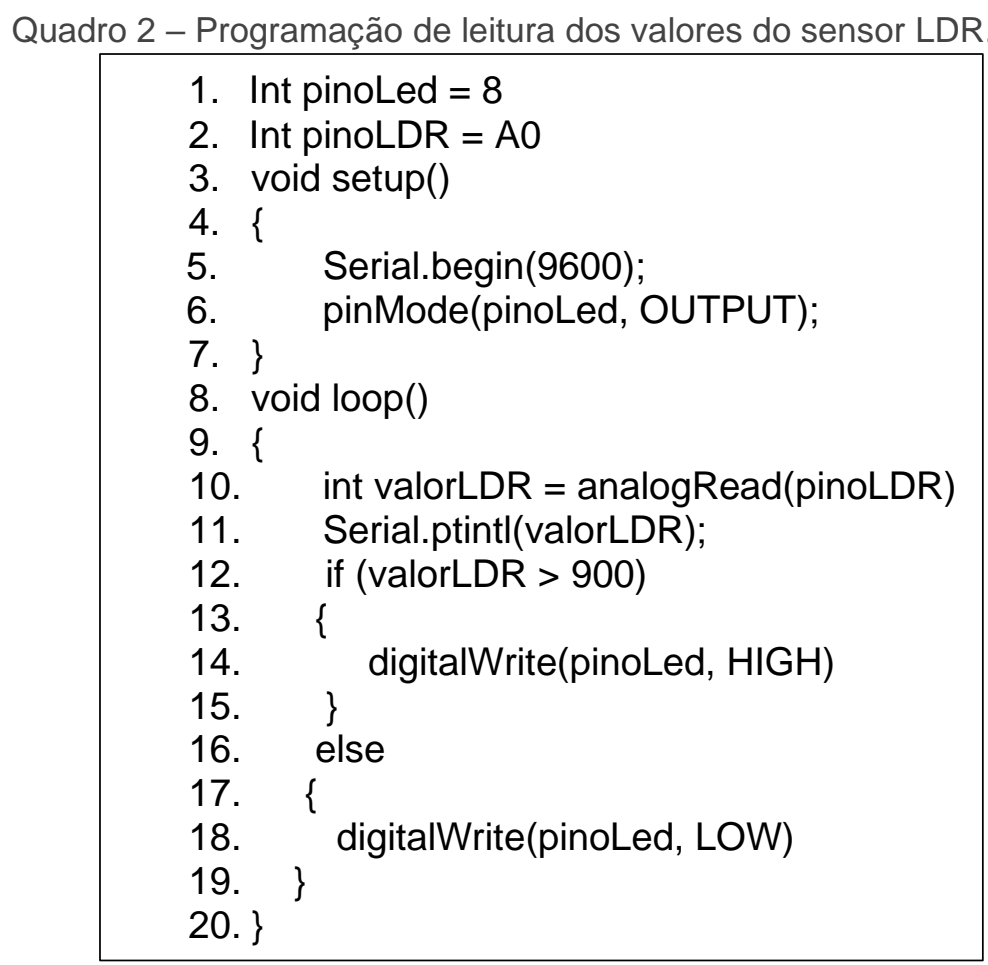

Fonte: Própria

Verifica-se pelo quadro 2 que a leitura do sensor LDR ocorre na linha 10 por meio

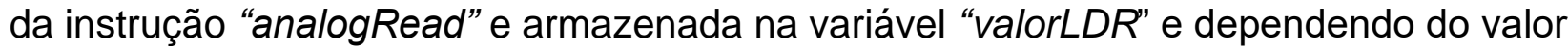
dessa variável, o led acenderá ou apagará. 


\subsection{Etapa final "Ida às compras"}

Para que os estudantes tenham uma ideia de custo e também onde encontrar as lojas virtuais de venda de componentes e dispositivos eletroeletrônicos, a tabela 1 apresenta a relação de componentes utilizados nas oficinas.

Tabela 1 - Lista dos componentes utilizados nos projetos 1 e 2.

\begin{tabular}{|l|c|c|}
\hline \multicolumn{1}{|c|}{ Descrição } & Qtde (oficina) & Qtde (individual) \\
\hline Fonte de tensão & 10 & 1 \\
\hline Pilhas AA de 1,5 V & 60 & 8 \\
\hline Suporte para 4 pilhas & 40 & 2 \\
\hline Protoboard 400 pontos & 10 & 1 \\
\hline Resistência $1 \mathrm{~K} \Omega(1 / 4 \mathrm{~W})$ & 30 & 3 \\
\hline Resistência $10 \mathrm{~K} \Omega(1 / 4 \mathrm{~W})$ & 30 & 1 \\
\hline Resistência $2,2 \mathrm{~K} \Omega(1 / 4 \mathrm{~W})$ & 10 & 1 \\
\hline Resistência $100 \Omega(1 / 4 \mathrm{~W})$ & 10 & 1 \\
\hline Resistência $220 \Omega(1 / 4 \mathrm{~W})$ & 10 & 1 \\
\hline Resistência 330 $\Omega(1 / 4 \mathrm{~W})$ & 10 & 1 \\
\hline Potenciômetro $100 \mathrm{~K} \Omega(0,2 \mathrm{~W})$ & 10 & 1 \\
\hline Led (5mm) vermelho & 10 & 1 \\
\hline Led (5mm) amarelo & 10 & 1 \\
\hline Led (5mm) verde & 10 & 1 \\
\hline Sensor LDR & 10 & 1 \\
\hline Botão de pulso & 10 & 1 \\
\hline Amplificador operacional LM324 & 10 & 1 \\
\hline Jumpers (macho-macho) & 120 & 10 \\
\hline Arduino Uno & & \\
\hline
\end{tabular}

Fonte: Própria

A tarefa dos participantes é fazer o levantamento de preço dos componentes listados na tabela 1 onde a coluna "Qtde (individual)" corresponde ao número mínimo de componentes para que cada estudante reproduza as oficinas nas suas garagens.

\section{CONSIDERAÇÕES FINAIS}

A estratégia adotada na metodologia teve foco no ensino fundamental ( $9^{\text {a }}$ série) e médio, como público-alvo. Pela experiência do PET em extensões desse tipo, a simplicidade da execução das tarefas e dos circuitos empregados causam muita satisfação nos estudantes porque possibilitam que comecem e finalizem os desafios colocados. Isso faz com que o público-alvo se sintam empoderado, gerando motivação e autonomia para estudos de outros projetos.

Os exemplos de circuitos eletroeletrônicos utilizados envolvem ações do nosso dia a dia como, por exemplo, acender e apagar uma luz por meio de chave e também de forma automática com o uso do sensor LDR, controlar o semáforo, enfim, situações que facilitam a visualização do problema e a respectiva solução, tanto em hardware como na programação. A programação do microcontrolador Arduino foi relativamente fácil, porém, serviu de estímulo para visualização de novos projetos, haja vista que o arduino é muito popular na internet o que garante apoio à aprendizagem em abundância.

Nas noções teóricas, além do uso prático da Lei de Ohm, a metodologia fez uso de dois gráficos, curva característica $(\mathrm{VxI})$ do led e o comportamento do LDR em função da intensidade de luz, com a intenção de fazer um vínculo com a física e com as funções que são estudadas na disciplina de matemática. 
Outro aspecto interessante a ser comentado é a etapa "ida às compras" porque, além de levantar o custo e onde encontrar os produtos, essa atividade forneceu mais um mecanismo de autoaprendizagem e ideias de soluções de diversos problemas, haja vista que muitas lojas virtuais oferecem projetos envolvendo circuitos eletroeletrônicos e programação aplicada em hardware para diversas situações do cotidiano.

A metodologia também contribui, em certa medida, para o itinerário formativo "formação técnica e profissional" da Base Nacional Comum Curricular (BNCC) do ensino médio.

Ao final, a metodologia empregada nessa iniciação tecnológica garantiu o despertar de vocações, não só para as áreas das engenharias, mas de uma forma geral em decorrência dos debates gerados ao final das oficinas. Todavia, a maioria dos participantes comentou que não sabe qual a profissão a ser seguida e que as oficinas semelhantes a essas, corroboram para o amadurecimento da escolha profissional.

\title{
Agradecimentos
}

Agradecemos ao apoio recebido pelo Programa de Educação Tutorial (PET) - MEC.

\section{REFERÊNCIAS}

ARDUINO. Documento de referência do Arduino. Disponível em: https://www.arduino.cc/reference/pt. Acesso em 2 fev. 2021.

BENITEZ, C. M. V. Eletricidade e eletrônica na prática. Disponível em: https://www.infolivros.org/livros-de-eletronica-gratis-pdf. Acesso em 23 out. 2020.

GAIER. M. B.. Aprendendo a programar em Arduino. Disponível em: https://www.academia.edu/41503370/. Acesso em 15 mar 2021.

LDR. Manual da eletrônica. Disponível em: https://www.manualdaeletronica.com.br/ldr-oque-e-como-funciona/. Acesso em 02 fev 2021.

LED. Como fazer as coisas. Disponível em: http://www.comofazerascoisas.com.br/comocalcular-o-resistor-adequado-para-um-led.html. Acesso em: 05 mar 2021.

\section{PETIANA EXTENSION FOCUSED ON TECHNOLOGICAL INITIATION OF BASIC EDUCATION STUDENTS}

\begin{abstract}
The present work is the result of one of the extensions carried out by PET AutoNet in the context of basic education students, comprising State schools, and with the objectives of awakening vocations and contributing to technological initiation as well as to the formative itinerary "technical training and professional" of the Base Nacional Comum Curricular (BNCC) of high school. In addition, the extension sought to stimulate the target audience for the areas of Engineering and its technologies. For these purposes, the article describes the methodology used based on two technological initiation projects. The first project is called "Hardware Workshop". The first problem of this workshop is to activate a lamp, represented
\end{abstract}


by a light emitting diode (led), by a key and by the LDR sensor, and the solution is the assembly of two electronic circuits using an operational amplifier LM324. The workshop is not only the assembly of the electronic circuit, theoretical notions are also introduced involving Ohm's Law, series and parallel association of resistors, operation of the light emitting diode (led), calculation of the resistance in series with the led, interpretation of the characteristic curve (IxV) of the led. The second project, "Applied Programming Workshop", is related to the application programming in the control of a traffic light and in the activation of a lamp, however, the solution of the problem is through the programming of the Arduino microcontroller. At the end of the extension, students' motivation is notorious, thanks to the methodology used that places students as protagonists of learning.

Keywords: Technological Initiation; Applied Programming; Electronic Circuits; Basic education; University Extension 